\title{
ETHYLENE PRODUCTION FROM DILUTED BIOETHANOL SOLUTIONS
}

Ilenia Rossetti ${ }^{1 *}$, Matteo Compagnoni ${ }^{1}$, Giorgia De Guido ${ }^{2}$, Laura A. Pellegrini ${ }^{2}$, Gianguido Ramis ${ }^{3}$, Stanislaw Dzwigaj ${ }^{*}$

${ }^{1}$ Dip. Chimica, Università degli Studi di Milano, INSTM Unit Milano-Università and CNR-ISTM, via C. Golgi, 19, I20133 Milano, Italy, ilenia.rossetti@unimi.it

${ }^{2}$ Dip. di Chimica, Materiali e Ingegneria Chimica “G. Natta”, Politecnico di Milano, P.zza Leonardo da Vinci 32, I20133 Milano, Italy

${ }^{3}$ Dip. di Ingegneria Civile, Chimica e Ambientale, Università degli Studi di Genova, P.le J.F. Kennedy 1, I-16129, Genova, Italy and INSTM Unit Genova

${ }^{4}$ Sorbonne Universités, UPMC Univ Paris 06, CNRS, UMR 7197, Laboratoire de Réactivité de Surface, F-75005, 4 place Jussieu, Paris, France, stanislaw.dzwigaj@upmc.fr

\begin{abstract}
Ethylene production by ethanol dehydration has been investigated over a set of HAlBEA zeolites. The effect on $\mathrm{Ni}$ addition (up to $3 \mathrm{wt} \%$ ) is explored as a mean to improve ethylene selectivity limiting the formation of heavier byproducts. The reaction temperature has been varied between 300 and $500^{\circ} \mathrm{C}$ and the effect of cofeeding water has been also explored. Both an increase of the operating temperature and of the water/ethanol ratio can improve stability to coking and thus catalyst life. The use of diluted bioethanol solutions showed beneficial as for catalyst stability. The effect of possible impurities present in less purified raw materials was also checked by testing two diluted second generation bioethanol solutions (50 and 90 vol \%).

A first reactor layout and the integration with the bioethanol purification strategy are also proposed, including two purification options much less energy demanding than traditional rectification.
\end{abstract}

Keywords: Ethylene production; Ethanol; Process intensification; Zeolite; Catalytic dehydration.

\section{INTRODUCTION}

At present, ca. $75 \%$ of petrochemical products are produced from ethylene, including acetaldehyde, acetic acid, ethylene oxide, ethylene glycol, ethylbenzene, chloroethanol, vinyl chloride, styrene, ethylene dichloride and vinyl acetate. It is also used as monomer to produce a variety of important products such as polyethylene, polyvinyl chloride and polystyrene. The main process for ethylene production at present is cracking of hydrocarbons, leading to $c a .99 \%$ of ethylene worldwide. ${ }^{[1,2]}$

\footnotetext{
*Corresponding authors: fax +39-02-50314300; email ilenia.rossetti@unimi.it; stanislaw.dzwigaj@upmc.fr
} 
To exploit new renewable based feedstocks for ethylene production, biomass-derived ethanol can be catalytically dehydrated as a sustainable alternative route. ${ }^{[3,4]}$ The bio-based polymers market is extensively growing (1.3 billion US dollar market with 35 \% growth between 2006 and 2011). The demand for renewable polyethylene (PE) corresponds to $10 \%$ of the global PE market whereas the present supply is $<1 \%$. However, for viable processes, a premium price for the products and/or low-cost feedstock are required and this point is still challenging. ${ }^{[5]}$ Therefore, routes to ethylene starting from less expensive feedstocks should be explored.

The availability of second generation bioethanol at a reasonable price ${ }^{[6]}$ may open the way to this important step towards the exploitation of biorefineries. However, the unit operations to achieve the concentration and final dehydration of the fermentation broth hugely affect bioethanol price, especially when $>99 \%$ purity is required, as for direct combustion or gasoline mixing purposes. Therefore, the possibility to use less concentrated bioethanol solutions as feedstock is an important step towards the economical sustainability of the process.

Ethylene may be produced through ethanol dehydration, catalyzed by acidic active sites. The reaction is endothermal and heat is commonly provided by cofeeding steam, which also allows preventing catalyst coking, which is also promoted by strong acidic sites. Such reaction environment opens up the intriguing possibility to use directly diluted bioethanol mixtures. Therefore, in this work we investigated the unconventional use of a diluted ethanol solution (ca. 50 vol \%) for ethylene production. Such feedstock may be simply obtained by flash concentration of the fermentation broth, so limiting very much the ethanol purification costs or, depending on the desired concentration, by using a feed split purification strategy which has been recently proposed by our group. ${ }^{[7]}$

Alumina is the most used and investigated catalyst for this application. However, besides coking problems, it suffers of competitive adsorption between ethanol and water. Therefore, the common strategy to add steam to prevent extensive deactivation induces significant drawbacks for catalytic activity. Zeolites have been suggested as alternative catalysts, but also in this case stability issues may arise due to coking and poor hydrothermal stability in the presence of steam. The catalytic performance of different zeolites have been reported for this application ${ }^{[2,8-11]}$ and very recently reviewed by Sun and Wang. ${ }^{[12]}$

We here selected BEA zeolite samples with optimized acidity. ${ }^{[11]}$ The BEA microporous structure is constituted by channels ca. $6.7 \AA$ in size, allowing the diffusion of ethanol with limited resistance, ${ }^{[13]}$ since almost all the accessible free volume of the pores is available given the characteristic molecular size of ethanol (ca. $3.8 \AA$ ). ${ }^{[14]}$ The effect of reaction conditions has been considered to optimize the selectivity to ethylene. Ni addition in different concentration has been 
also explored as a further mean to tune process selectivity towards ethylene. Indeed, Ni is active for the reforming of higher olefins and hydrocarbons, thus it can possibly improve catalyst selectivity to ethylene. Finally, the best performing catalyst has been tested also with real bioethanol solutions to account for possible impurities contained in a less purified feed. Catalyst durability has been also taken into account through a prolonged time-on-stream test and the prepared catalysts were characterised by various techniques both fresh and spent.

\section{MATERIALS AND METHODS}

\section{Catalyst Preparation}

Details on catalyst preparation can be found elsewhere. ${ }^{[11]}$ Briefly, a T tetraethylammonium BEA (TEABEA) zeolite with Si/Al ratio of 17 (mol/mol) nominal, provided by RIPP (China) was calcined in air $\left(100{ }^{\circ} \mathrm{C} / \mathrm{h}\right)$ at $550{ }^{\circ} \mathrm{C}$ for $15 \mathrm{~h}$ to remove the organic template and then treated two times with $400 \mathrm{~mL}$ of $0.1 \mathrm{~mol} / \mathrm{L} \mathrm{NH}_{4} \mathrm{NO}_{3}$ solution for $3 \mathrm{~h}$ in order to exchange $\mathrm{K}^{+}$and $\mathrm{Na}^{+}$ions present in industrial BEA zeolite with $\mathrm{NH}_{4}{ }^{+}$ion. The obtained material was washed with distilled water and dried overnight at $90^{\circ} \mathrm{C}$. The $\mathrm{NH}_{4} \mathrm{AlBEA}$ samples was calcined in air $\left(100{ }^{\circ} \mathrm{C} / \mathrm{h}\right)$ for $3 \mathrm{~h}$ at $500{ }^{\circ} \mathrm{C}$ to remove $\mathrm{NH}_{3}$ and obtain the acidic form of the zeolite BEA, HAlBEA.

$\mathrm{Ni}$ was added by wet impregnation from a $\mathrm{Ni}\left(\mathrm{NO}_{3}\right)_{2} \cdot 6 \mathrm{H}_{2} \mathrm{O}$ solution. Proper amount of Ni precursor was dissolved in $200 \mathrm{~mL}$ water and the solid suspension was stirred for $24 \mathrm{~h}$ at room temperature at $\mathrm{pH}$ of 3.3. Then, the suspension was stirred in evaporator under vacuum of a water pump for $2 \mathrm{~h}$ in air at $60{ }^{\circ} \mathrm{C}$ until the water was evaporated. Three samples with 0.5, 1.5 and $3.0 \mathrm{wt} \%$ of Ni were obtained and labeled as Ni0.5HAlBEA, Ni1.5HAlBEA and Ni3.0HAlBEA (Table 1). The composition of the tested samples is reported in Table 1.

Table 1. Nomenclature, preparation parameters and main physical-chemical properties of the samples prepared.

\begin{tabular}{|c|c|c|c|c|}
\hline Sample & Code & $\begin{array}{c}\text { Initial Si/Al } \\
\text { (atom/atom) }\end{array}$ & Post-treatment & $\begin{array}{c}\mathrm{Ni} \\
\text { content } \\
\text { (wt \%) }\end{array}$ \\
\hline 1 & HAlBEA & 17 & Calcination & 0 \\
\hline 2 & Ni 0.5 HAlBEA & 17 & Calcination & 0.5 \\
\hline 3 & Ni 1.5 HAlBEA & 17 & Calcination & 1.5 \\
\hline 4 & Ni3.0HAlBEA & 17 & Calcination & 3.0 \\
\hline
\end{tabular}




\section{Activity Testing}

Details on the equipment for activity testing have been previously reported elsewhere.[15,16] Briefly, the catalysts (ca. $0.5 \mathrm{~g}, 0.15-0.25 \mathrm{~mm}$ particle size) were diluted $1: 3$ (vol/vol) with SiC of the same size. The void space of the reactor was filled with quartz beads, $c a .1 \mathrm{~mm}$ in size. The sample was activated in $50 \mathrm{~cm}^{3} / \mathrm{min}$ of a $20 \% \mathrm{H}_{2} / \mathrm{N}_{2}$ gas mixture, while heating by $10{ }^{\circ} \mathrm{C} / \mathrm{min}$ up to $625^{\circ} \mathrm{C}$ for $1 \mathrm{~h}$.

Activity testing was carried out by feeding $0.017 \mathrm{~cm}^{3} / \mathrm{min}$ of a $\mathrm{X}: 1(\mathrm{~mol} / \mathrm{mol}) \mathrm{H}_{2} \mathrm{O}: \mathrm{CH}_{3} \mathrm{CH}_{2} \mathrm{OH}(\mathrm{X}$ $=3,2,1,0$ ) liquid mixture by means of a Hitachi, mod. L7100, HPLC pump, added with 56 $\mathrm{cm}^{3} / \mathrm{min}$ of $\mathrm{N}_{2}$, used as internal standard, and $174 \mathrm{~cm}^{3} / \mathrm{min}$ of He. Such dilution of the feed stream was calibrated so to keep the reactants mixture in the vapour phase even at zero conversion at the reactor outlet.

The activity tests were carried out at atmospheric pressure, GHSV $=2500 \mathrm{~h}^{-1}$ referred to the ethanol + water gaseous mixture (76500 $\mathrm{h}^{-1}$ including the inert gases flow rate), at temperatures ranging from 300 to $500{ }^{\circ} \mathrm{C}$.

The analysis of the out-flowing gas was carried out by GC analysis. The analytical system allows to quantify simultaneously ethanol, ethylene, water, ethane, $\mathrm{H}_{2}, \mathrm{CO}, \mathrm{CO}_{2}$, acetaldehyde, propane, propylene, diethylether and higher hydrocarbons if needed. Repeated analyses of the effluent gas were carried out every hour and the whole duration of every test at each temperature was $8 \mathrm{~h}$. The raw data, expressed as $\mathrm{mol} / \mathrm{min}$ of each species outflowing from the reactor, averaged after 4-8 hon-stream, have been elaborated as described here below:

Products distribution: $\quad \mathrm{Y}_{\mathrm{i}}=\mathrm{mol} \mathrm{i} / \Sigma(\mathrm{mol} \mathrm{i})$

\section{C balance:}

$\left.100-\left(\left(\left(\mathrm{mol} \mathrm{CH}_{3} \mathrm{CH}_{2} \mathrm{OH} * 2\right)\right)_{\text {in }}-\Sigma\left(\mathrm{mol} \mathrm{Ci}^{*} \chi_{\mathrm{i}}\right)_{\text {out }}\right) /\left(\left(\mathrm{mol} \mathrm{CH}_{3} \mathrm{CH}_{2} \mathrm{OH} * 2\right)\right)_{\text {in }}\right) * 100$

Conversion: $\mathrm{X}_{\mathrm{i}}=(\mathrm{mol} \mathrm{i}$ in $-\mathrm{mol} \mathrm{i}$ out $) / \mathrm{mol} \mathrm{i}_{\text {in }} \quad \mathrm{i}=\mathrm{H}_{2} \mathrm{O}, \mathrm{CH}_{3} \mathrm{CH}_{2} \mathrm{OH}$

Selectivity: $S_{i}=\left(m o l i / v_{i}\right) /(m o l$ ethanol in - mol ethanol out $)$

Where $i=$ products detected, dry basis; $\chi_{i}=$ number of $\mathrm{C}$ atoms in the $i$-th molecule; $v_{i}=$ stoichiometric coefficient of species $i$ in the dehydration or other parasitic reaction.

\section{RESULTS AND DISCUSSION}




\section{Thermodynamic Considerations}

Using water + ethanol mixtures for ethylene production by dehydration is not intuitive, being a dehydration reaction, and the operating conditions should be properly checked from a thermodynamic point of view. The equilibrium products distribution has been evaluated by using the Aspen Plus ${ }^{\circledR}$ process simulation tool, adopting i) the predictive Soave-Redlich-Kwong (PSRK) thermodynamic package and ii) the Non-Random-Two-Liquid (NRTL) model with Wilson mixing rules to model non-ideality in liquid phase, coupled with the SRK equation of state to model real gas phases. Both models gave rise to the same results.

Equilibrium composition has been evaluated by using a Gibb’s reactor model. The reactor feed was defined (pure ethanol or ethanol + water) and a population of allowed compounds was associated to the reactor, including the reactants and all the products of the reactions that are likely to occur in the reactor itself (including ethanol decomposition, steam reforming products and coke model compounds such as benzene and light polycondensed aromatic species). This is a very critical choice because if some reactions are neglected, unreliable and inconsistent product previsions may be obtained.

A detailed thermodynamic analysis of the process carried out in the presence or absence of water is reported elsewhere. ${ }^{[11]}$ According to that results, even if the addition of water slightly unfavoured ethanol conversion (with negligible effect on the selectivity to ethylene), it helped in limiting coke formation. The thermodynamically favoured pathway at low temperature was ethanol decomposition to form methane, whereas at higher temperature $\left(>500^{\circ} \mathrm{C}\right)$ syngas was the favoured product, due to ethanol steam reforming.

These considerations allow concluding that when ethylene is the desired outcome, the optimisation of catalyst selectivity should be carefully carried out. The catalyst should turn the reaction pathway towards thermodynamically less favourable routes, i.e. ethanol dehydration rather than decomposition. Therefore, materials and conditions must be selected to drive the reaction under kinetic regime and not under thermodynamic control, which is not the typical scope in designing catalysts. In this way, it is possible to achieve the desired ethylene selectivity by using diluted bioethanol solutions, a much cheaper feedstock than pure ethanol.

\section{Effect of Ni Loading on Ethanol Dehydration to Ethylene}

The effect of acidity on catalyst performance has been recently investigated elsewhere. ${ }^{[1]}$ The zeolite HAIBEA was selected for the present work due to its superior selectivity to ethylene when preliminarily tested at $500{ }^{\circ} \mathrm{C}$, water $/$ ethanol ratio $=3: 1(\mathrm{~mol} / \mathrm{mol})$ and $1.5 \mathrm{wt} \% \mathrm{Ni}$ loading. Under such reaction conditions the catalyst completely converted ethanol, with $99 \pm 3 \%$ selectivity to 
ethylene. A life test was also performed on catalyst B for 80 h-on-stream, without any evidence of significant deactivation.

A comparative test performed on commercial $\gamma-\mathrm{Al}_{2} \mathrm{O}_{3}$, of the type used for industrial ethanol dehydration, led to complete ethanol conversion, but much more limited selectivity to ethylene, i.e. $80 \pm 7 \%$.

At constant, low Ni loading, acidity was decreased by increasing the $\mathrm{Si} / \mathrm{Al}$ ratio either by selecting different native zeolites or by postsynthesis dealumination, leading to decreasing acidity. The sample characterised by very strong Lewis acid sites led to high dehydration activity, but followed by progressive coking of the strongest acidic sites. By contrast, too low acidity led to lower dehydration activity. The alumina commercial catalyst for ethanol dehydration led to lower ethylene selectivity and lower carbon balance due to stronger Lewis acidity than the present BEA zeolites.

The native HAlBEA zeolite, without $\mathrm{Ni}$ addition, was active for ethanol dehydration and led to higher selectivity than the reference alumina sample. However, it also led to the formation of undesired byproducts, such as diethylether. Furthermore, catalyst performance was rather unstable during time-on-stream (Fig. 1). Heavier compounds an diethylether have been frequently reported in the literature as byproducts for this process. In order to limit their selectivity we explored the addition of a metal phase, e.g. Ni, in order to promote their possible decomposition, being more reformable compounds with respect to ethanol and ethylene.

Fig. 1: Ethanol conversion and selectivity to ethylene and diethylether (DEE) at different temperature on catalyst HAlBEA.

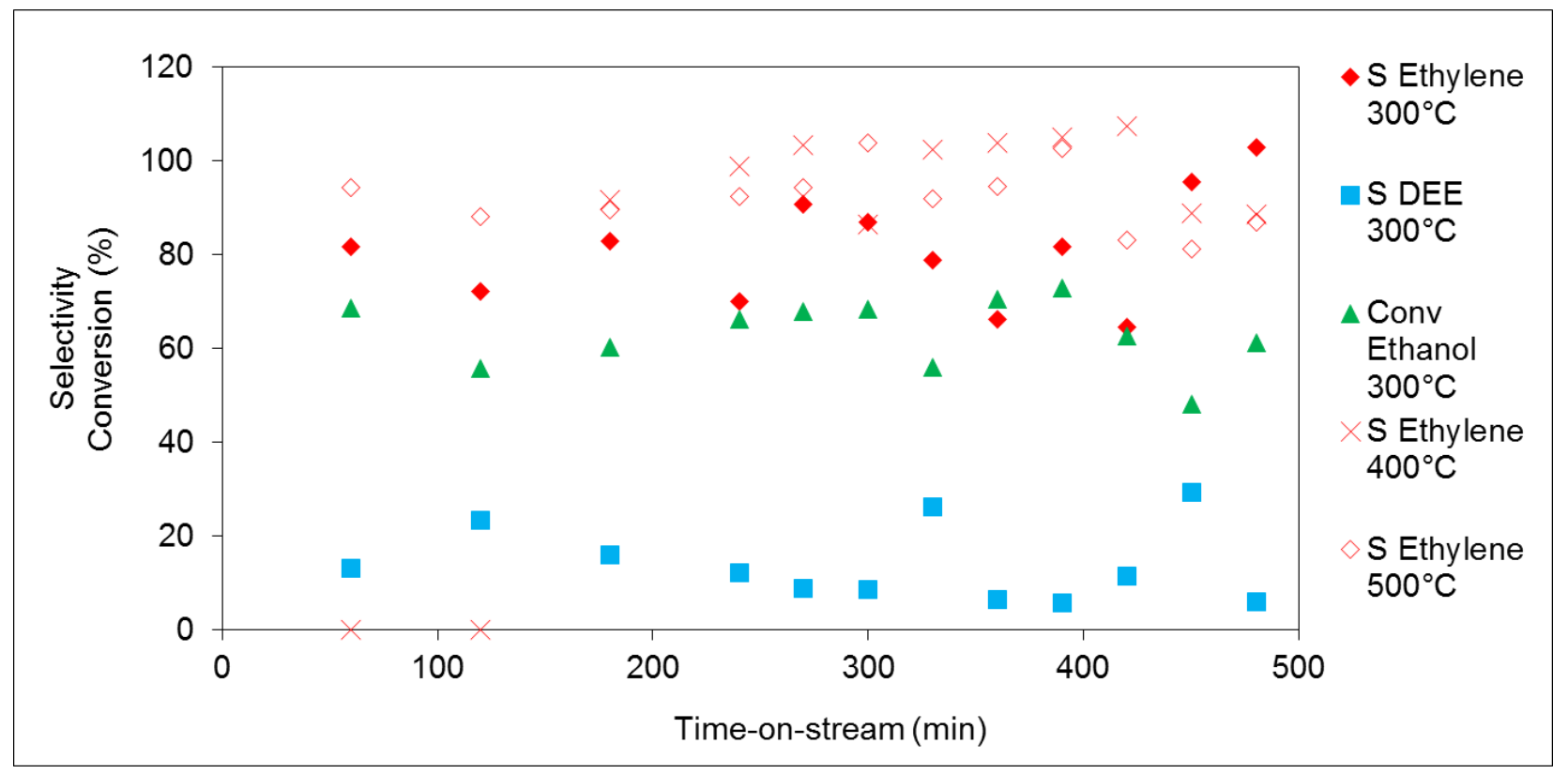


The results are reported in Table 2. Ni addition, without significantly lower selectivity to ethylene, allowed indeed to stabilise catalyst performance. This is visible by the lower spread of the carbon balance and selectivity to ethylene for the Ni containing catalysts with respect to the acidic ones. Furthermore, Ni containing catalysts completely suppressed the formation of heavier byproducts, such as diethylether, possibly present at the lowest temperature.

Table 2. Results of activity testing at different temperature after activation at $800{ }^{\circ} \mathrm{C}$, water/ethanol $=3: 1 \mathrm{~mol} / \mathrm{mol}, \quad$ GHSV $=2500 \mathrm{~h}^{-1}$. Effect of Ni loading on HAlBEA zeolite. Commercial alumina as reference.

\begin{tabular}{|l|l|l|l|l|l|l|}
\hline $\mathbf{T}\left({ }^{\circ} \mathbf{C}\right)$ & Ni loading (wt \%) & $\mathbf{0}$ & $\mathbf{0 . 5}$ & $\mathbf{1 . 5}$ & $\mathbf{3 . 0}$ & $\boldsymbol{\gamma}-\mathbf{A l}_{2} \mathbf{O}_{3}$ \\
\hline $\mathbf{5 0 0}$ & Ethanol conversion (\%) & 100 & 100 & 100 & 100 & $100 \pm 0.00$ \\
& C balance (\%) & $96 \pm 8$ & $96 \pm 2$ & $98 \pm 3$ & $98 \pm 2$ & $88 \pm 7$ \\
\cline { 2 - 7 } & Selectivity ethylene (\%) & $92 \pm 7$ & $88 \pm 4$ & $99 \pm 3$ & $72 \pm 3$ & $80 \pm 7$ \\
\hline \multirow{4}{*}{$\mathbf{4 0 0}$} & Ethanol conversion (\%) & 100 & 100 & - & 100 & - \\
\cline { 2 - 7 } & C balance (\%) & $102 \pm 8$ & $102 \pm 2$ & - & $103 \pm 2$ & - \\
\cline { 2 - 7 } & Selectivity ethylene (\%) & $98 \pm 8$ & $99 \pm 2$ & - & $96.6 \pm 1.3$ & - \\
\hline \multirow{3}{*}{$\mathbf{3 0 0}$} & Ethanol conversion (\%) & $64 \pm 7$ & $67 \pm 7$ & - & $89 \pm 5$ & - \\
\cline { 2 - 7 } & C balance (\%) & $105 \pm 13$ & $100 \pm 7$ & - & $103 \pm 3$ & - \\
\cline { 2 - 7 } & Selectivity ethylene (\%) & $82 \pm 13$ & $82 \pm 7$ & - & $98 \pm 2$ & - \\
\cline { 2 - 7 } & Selectivity diethylether (\%) & 15 & 15 & - & - & - \\
\hline
\end{tabular}

\section{Effect of Reaction Conditions}

Tables 2 and 3 report the effect of variable reaction conditions. A decrease of temperature to $400^{\circ} \mathrm{C}$ allowed to maintain full ethanol conversion and $100 \%$ to ethylene especially at low or nil $\mathrm{Ni}$ loading. A further decrease of reaction temperature decreased conversion unacceptably if no enough $\mathrm{Ni}$ was present. The higher ethanol conversion for the highest $\mathrm{Ni}$ loading could be eventually attributed to higher steam reforming activity. This hypothesis is ruled out as demonstrated by the almost quantitative selectivity to ethylene. On the contrary, a high Ni amount led to the formation of additional middle strength Lewis acidic sites that were beneficial for this application at very low reaction temperature. By looking to the products spectrum, a process can be designed that in one step can fully convert ethanol to ethylene. If water is added, it can be rather easily separated by condensation at reactor outlet together with water formed during the dehydration reaction. In this 
light, optimal reaction conditions were then considered $400{ }^{\circ} \mathrm{C}$ and the best Ni loading $0.5 \mathrm{wt} \%$, at least among those here tested.

Table 3. Results of activity testing at $400{ }^{\circ} \mathrm{C}$ for the Nio.5HAlBEA catalyst after activation at $800{ }^{\circ} \mathrm{C}$, water/ethanol $=3: 1 \mathrm{~mol} / \mathrm{mol}, \quad \mathrm{GHSV}=2500 \mathrm{~h}^{-1}$. Effect of water/ethanol ratio and of ethanol origin.

\begin{tabular}{|l|c|c|c|c|c|c|}
\hline $\begin{array}{c}\text { Water/ethanol } \\
\text { (mol/mol) }\end{array}$ & $\mathbf{3 : 1}$ & $\mathbf{2 : 1}$ & $\mathbf{1 : 1}$ & $\mathbf{0 : 1}$ & $\mathbf{3 : 1 ~ B E 5 0}$ & $\mathbf{3 : 1 ~ B E 9 0}$ \\
\hline $\begin{array}{l}\text { Ethanol } \\
\text { conversion (\%) }\end{array}$ & 100 & 100 & 100 & 100 & 100 & 100 \\
\hline C balance (\%) & $102 \pm 2$ & $98 \pm 5$ & $99 \pm 7$ & $100 \pm 3$ & $99 \pm 2$ & $103 \pm 2$ \\
\hline $\begin{array}{l}\text { Selectivity } \\
\text { ethylene (\%) }\end{array}$ & $99 \pm 2$ & $95 \pm 5$ & $96 \pm 7$ & $98 \pm 3$ & $96 \pm 2$ & $98 \pm 3$ \\
\hline
\end{tabular}

Therefore, further experiments were carried out on this sample at $400^{\circ} \mathrm{C}$ by varying the water/ethanol ratio. According to the results of Table 3, no significant variation of catalyst performance was observed by using pure ethanol or diluted ethanol solutions, confirming the intriguing possibility to adopt such less purified, thus less expensive, raw material for ethylene production. Indeed, full conversion was always achieved, with satisfactory carbon balance and substantially quantitative selectivity to ethylene. Thus, the addition of water to ethanol under the present reaction conditions did not inhibit the dehydration reaction. On the contrary, a more stable behaviour of the catalyst during time-on-stream tests was observed at the highest water/ethanol ratio.

The highest productivity of ethylene has been obtained at $400^{\circ} \mathrm{C}$ with both the 0.5 and 3 wt \% NiHAlBEA catalysts and corresponded to ca. $18 \mathrm{kmol} / \mathrm{h} \mathrm{kg}$ cat, corresponding to the complete conversion of the ethanol in the feed.

\section{Performance with Real Bioethanol Feed}

In order to explore the effect of possible impurities present in a less purified bioethanol feedstock, we collected two samples of second generation bioethanol, kindly supplied by the Mossi\&Ghisolfi group. The two samples were obtained after flash separation (50 vol \%, called BE50) and after rectification (90 vol \%, called BE90) of the raw beer. Their preliminary characterisation revealed the presence of compounds of possible concern. Indeed, higher alcohols were found $\left(\mathrm{C}_{3}-\mathrm{C}_{5}\right.$ saturated alcohols up to 0.37 wt \% for BE90 and 0.15 wt \% for BE50), which may lead to more 
reactive and easily polymerisable olefins upon dehydration. Being these data expressed as wt \%, they absolute amount is substantially identical in the two samples (their wt \% changes just following dilution) and thus they are not effectively eliminated by rectification. In addition, sulphates (0.86 ppm for BE90, 1 ppm for BE50) and reduced sulphur-based compounds, possible poisons for the catalyst (0.3 ppm for BE90 and 0.7 ppm for BE50) were present. These latter Scontaining compounds can be decreased by rectification, though not fully eliminated in BE90, and may cause catalyst deactivation.

By looking at the results in Table 3 and Fig. 2, similar selectivity to ethylene was obtained when using BE50 or BE90 with respect to pure ethanol (i.e. 99.9 vol \%).

Fig. 2: Selectivity to ethylene and other by-products for catalyst $\mathrm{Ni} 0.5 \mathrm{HAlBEA}, \mathrm{T}=400{ }^{\circ} \mathrm{C}$, water/ethanol = 3, with a) BE90, b) BE50. DEE = diethylether.

a)

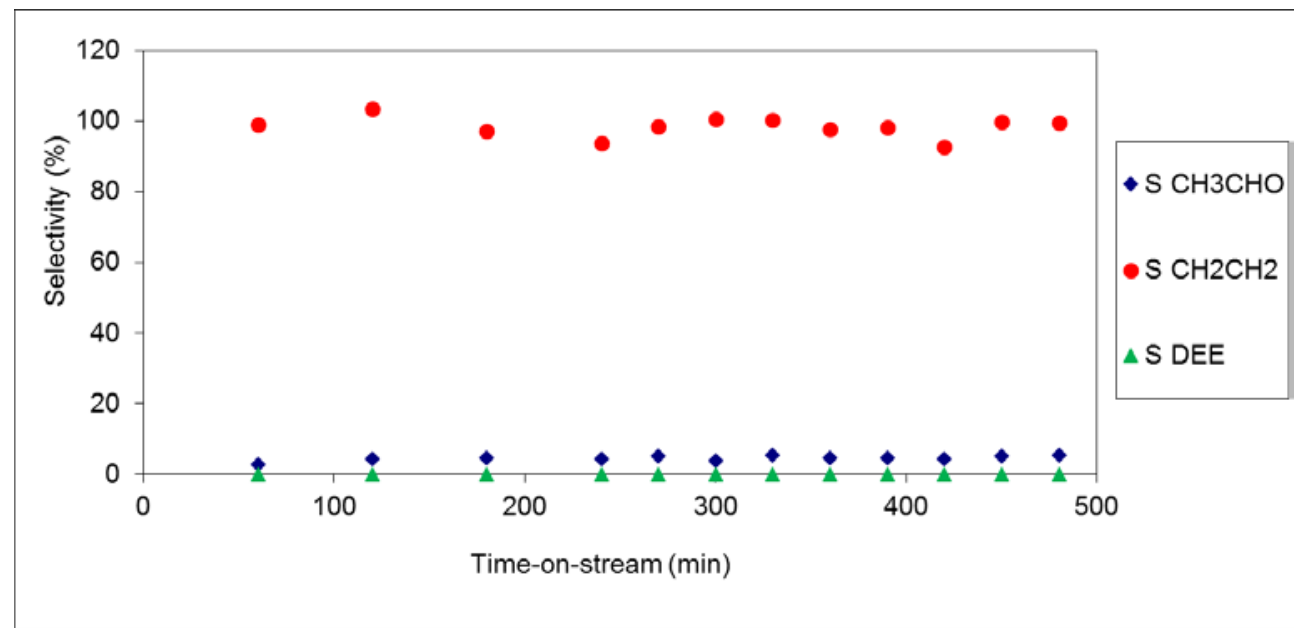

b)

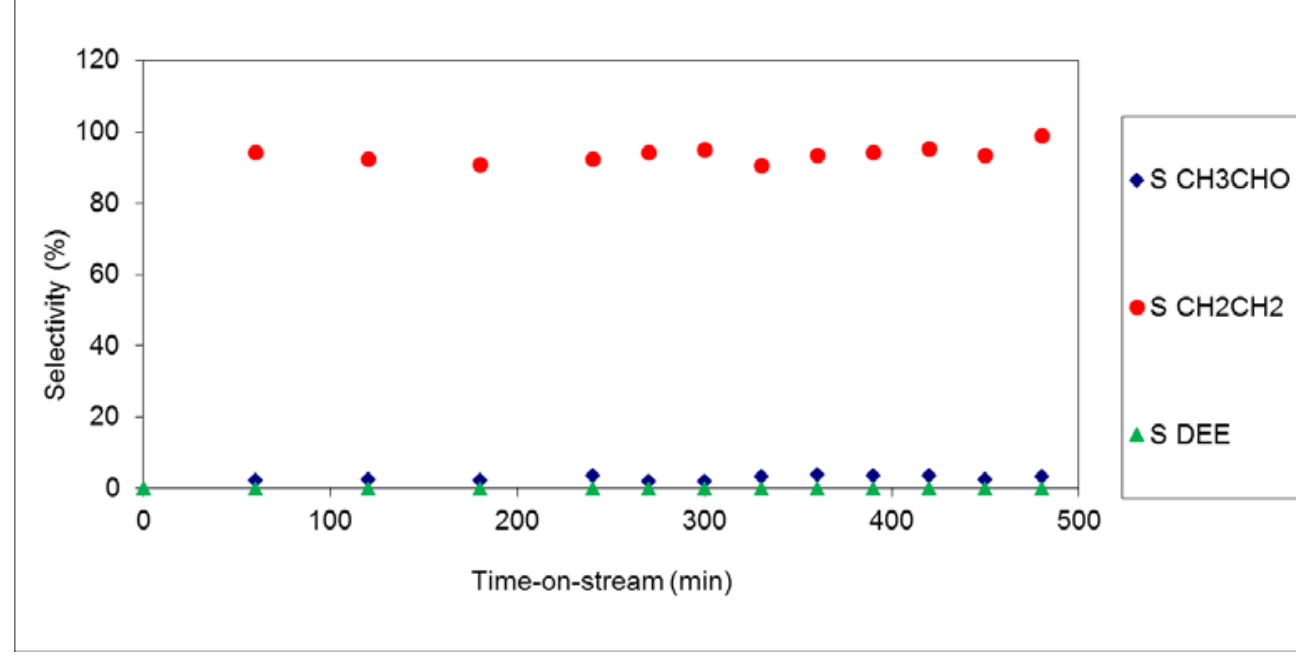




\section{Process Integration}

\section{Dehydration reactor}

The selected water/ethanol $=3 \mathrm{~mol} / \mathrm{mol}$ feed is particularly interesting for different reasons. This composition corresponds to $\mathrm{ca}$. $50 \mathrm{vol} \%$ mixture, which can be easily obtained from a fermentation broth by flash separation. ${ }^{[7]}$ This mixture has to be further rectified with huge costs if absolute ethanol is desired. Therefore, the possibility to use $50 \mathrm{vol} \%$ ethanol allows a feed sufficiently purified from minerals and heavier compounds, but its separation costs are minimal with respect to further azeotropic distillation and anhydrification. ${ }^{[7]}$ In a biorefinery scenario, bioethanol is produced and transformed into chemicals locally. Thus, using a cheaper feedstock with high water content is more economically advantageous and environmentally sustainable.

Another key point is to check if heating up the ethanol dehydration reactor when cofeeding water requires sustainable additional energy input to generate steam than vaporising pure ethanol.

Two different cases have been considered, represented in Fig. 3. In case b) internal heat recovery is accomplished, so that spent steam is used to preheat the diluted bioethanol feed, to vaporise the water co-fed with ethanol. This internal heat recovery can be very efficient since additional water is produced during dehydration, allowing more steam at reactor outlet. Additionally, water condensation carried out in the heat exchanger represents a very easy method for the purification of ethylene, since no other significant byproducts are present, at difference with most literature.

The duty of the heater (Fig. $3 a)$ to bring the feed $(0.25 \mathrm{kmol} / \mathrm{h}$ ethanol $+0.75 \mathrm{kmol} / \mathrm{h}$ water $)$ from $25{ }^{\circ} \mathrm{C}$ to $500{ }^{\circ} \mathrm{C}$ is ca. $19 \mathrm{~kW}$. Additional $3.2 \mathrm{~kW}$ should be furnished to the dehydration reactor. The reactor was operated at $500{ }^{\circ} \mathrm{C}$ and completely converted ethanol to $0.25 \mathrm{kmol} / \mathrm{h}$ ethylene +1 $\mathrm{kmol} / \mathrm{h}$ water (the feed + reaction product), as in our case. If the configuration is the one reported in Fig. $3 b$, the heater just brings the temperature to specification, requiring $c a .1 \mathrm{~kW}$, because most of the heat needed to vaporise the feed is obtained by cooling and condensation of the water outflowing the reactor. No significant change of the duty is observed while operating the reactor at $300{ }^{\circ} \mathrm{C}(1.05 \mathrm{~kW})$ with respect to $500{ }^{\circ} \mathrm{C}(1.08 \mathrm{~kW})$ in this last configuration (Fig. $\left.7 \mathrm{~b}\right)$.

Therefore, the use of cofeeding water and the operation at temperature possibly higher than those observed in the literature $\left(250-350^{\circ} \mathrm{C}\right)$ allow to achieve full ethanol conversion and ca. 99\% 
selectivity to ethylene, without heavier byproducts. This has important practical implications from the point of view of products separation easiness and to improve catalyst life.

Fig. 3: Feed vaporisation scheme: a) Base case without internal heat recovery or b) with a recovery heat exchanger.

a)

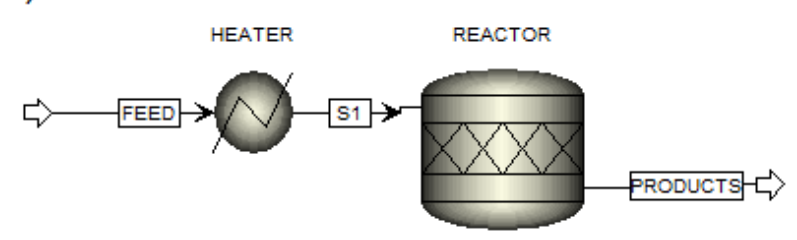

b)

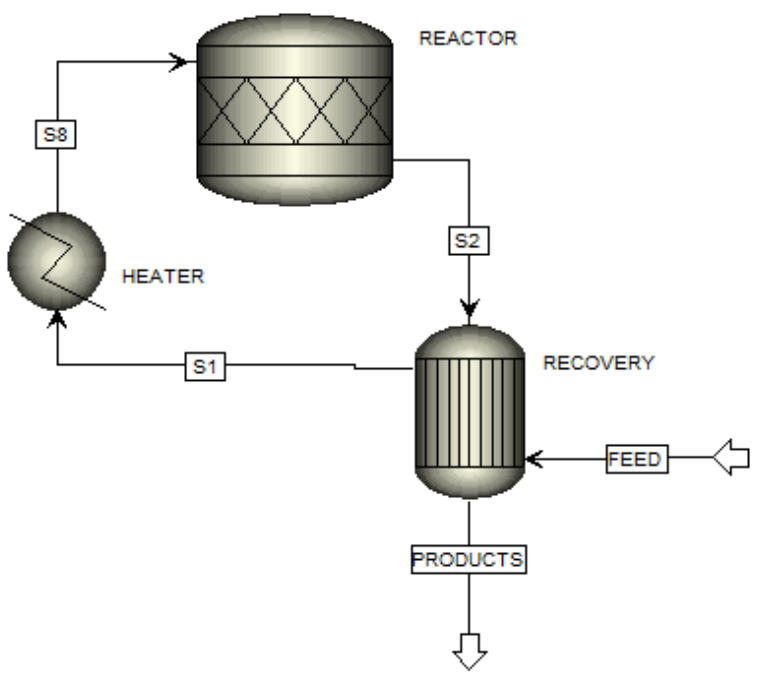

Bioethanol purification

The production of diluted bioethanol to be used for ethylene production reaction can involve purification strategies different from those commonly adopted for producing the raw material designated for gasoline blending, which has to meet much higher purity levels (> 99 vol \%).

We already demonstrated that the use of diluted ethanol is also technically feasible for the cogeneration of heat and power (hereafter denoted as CHP unit) described in a previous work. ${ }^{[7]}$ Therefore, to cope with these two different applications where limited bioethanol purification is required, the purification strategy has been investigated for determining a suitable solution, which allows to reduce the purification costs. The competitiveness of the whole technology can thus be improved.

A first solution is to use a single stage unit for bioethanol purification, i.e. a flash drum. This kind of unit is characterized by very limited installation costs with respect to a rectification column and the main operating cost is constituted by the duty. Very limited duty is required to obtain ca. 25 mol $\%$ ethanol, corresponding to the highest water/ethanol molar ratio here explored (Fig. 4). If a $10 \mathrm{wt}$ \% (i.e., about $4 \mathrm{~mol} \%$ ) bioethanol mixture were concentrated in a flash drum, the required duty severely increases in case of lower desired concentration due to a larger amount of water to be vaporized and the recovery of ethanol in the vapor phase increases up to $93.6 \%$ (Fig. 4). 
Figure 4. Duty and ethanol recovery for concentration of a $10 \mathrm{wt} \%$ bioethanol solution in a flush drum.

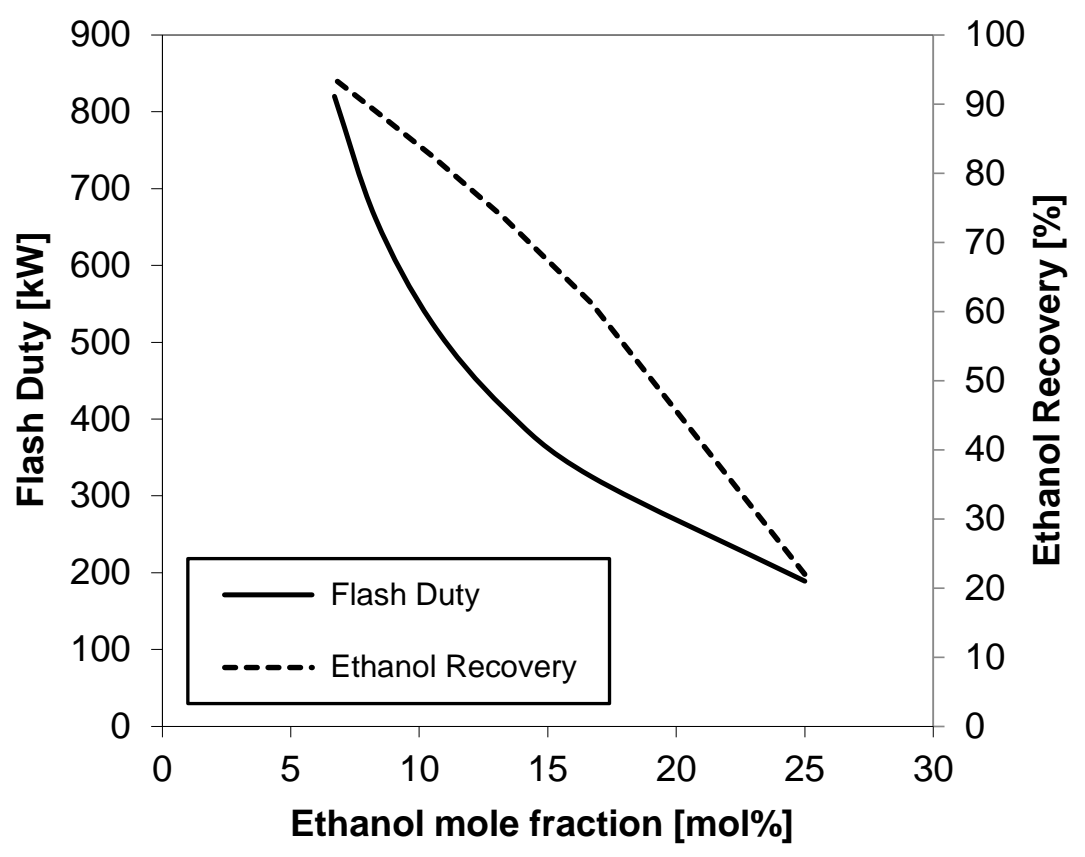

A different process scheme has been also explored in order to increase the ethanol recovery, while limiting the energy consumption of the concentration step. The scheme, already described by Rossetti et al. ${ }^{[7]}$ and illustrated in Figure 5 for the sake of clarity, processes only a fraction of the fermentation broth by concentration in a distillation column whose energy consumption at the bottom reboiler is lower for more diluted bioethanol mixtures (Fig. 6).

Therefore, depending on the desired water/ethanol ratio selected for this specific application, different purification strategies can be available to minimize process costs and improve efficiency.

Figure 5. Scheme of the concentration section proposed for producing diluted bioethanol limiting the energy consumptions. 


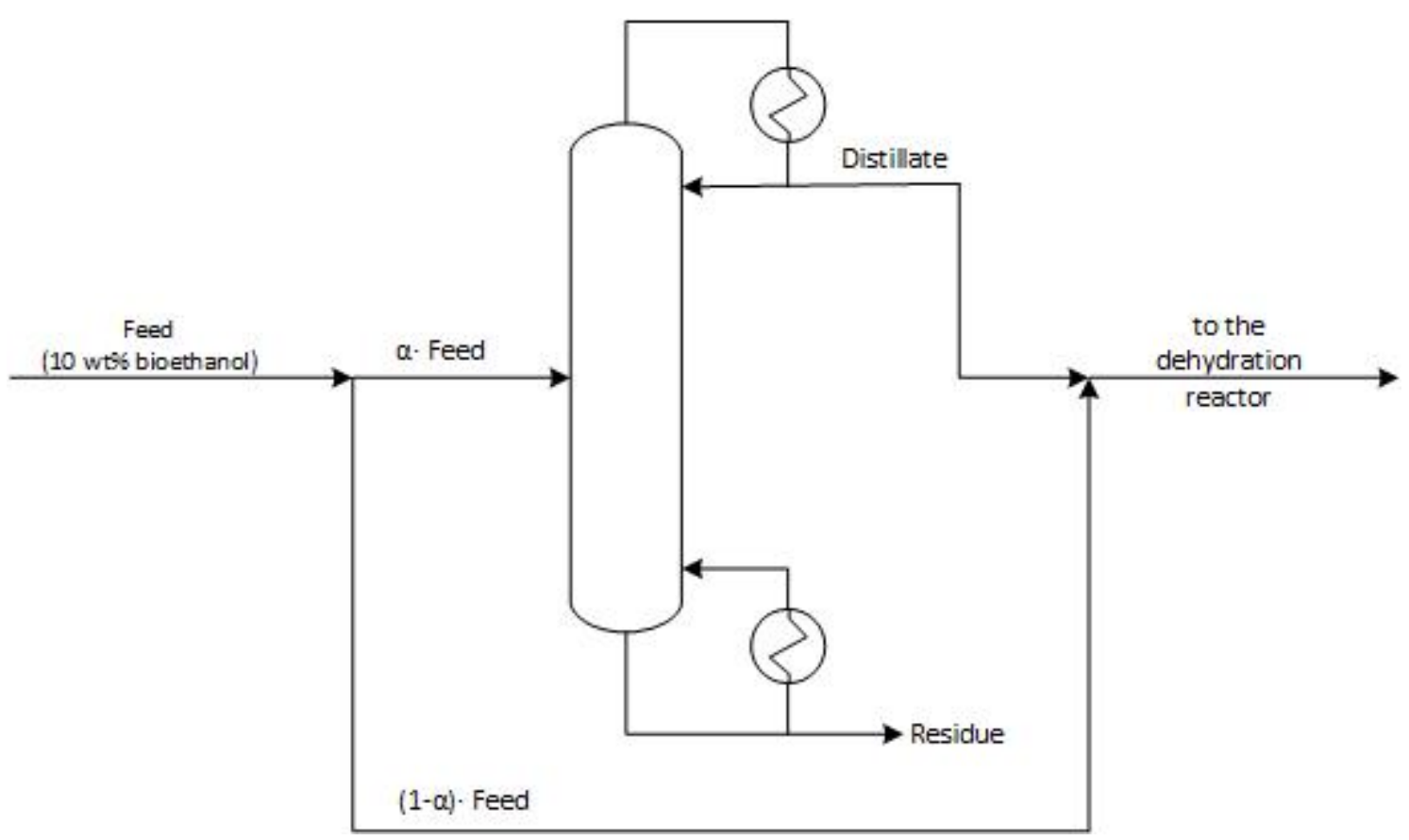

Figure 6. Reboiler duty required for bioethanol concentration by the process scheme illustrated in Figure 5.

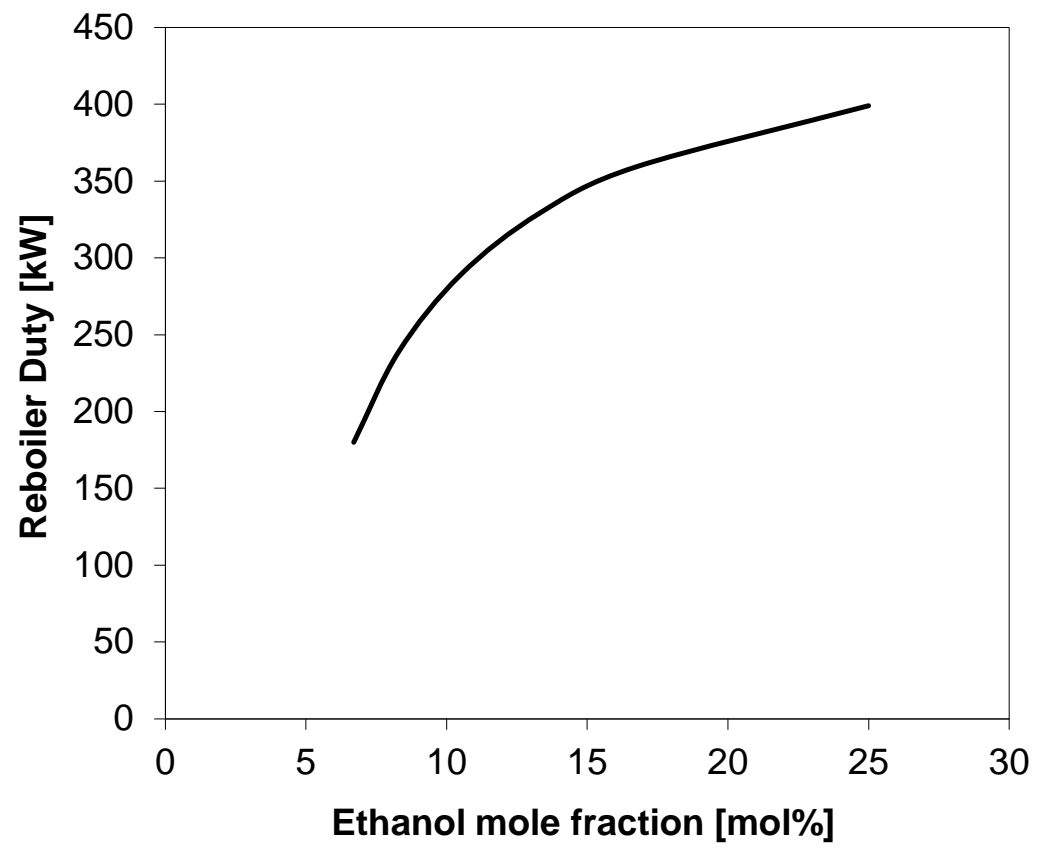

\section{CONCLUSIONS}

The ethanol dehydration reaction to ethylene has been carried out over HAlBEA and Ni containing HAlBEA catalysts. Full conversion of the reactant has been attained at temperature higher than 300 ${ }^{\circ} \mathrm{C}$. Ethylene was the main product, accompanied by diethylether at the lowest operating 
temperature. In order to limit byproducts formation and to improve both the selectivity to ethylene and the stability of the catalyst, small amounts of Ni were added in HAlBEA zeolite. This induced some additional acidity to improve activity at low temperature, but most of all led to quantitative selectivity to ethylene.

The addition of water in different amounts in the feed was also explored as a method to improve the stability towards coking. The satisfactory performance of the catalysts at relatively high water/ethanol ratio (up to $3: 1 \mathrm{~mol} / \mathrm{mol}$ ) opens the way to the use of diluted, i.e. less purified and less expensive, bioethanol solutions for this application. Therefore, two samples of diluted second generation bioethanol (50 and $90 \mathrm{vol} \%$ ) were used to check for the effect of possible impurities, which was negligible.

Two different purification strategies have been then compared, leading to possible options to obtain diluted and poorly expensive bioethanol solutions. One is the separation through a flash drum, the other is feed splitting, each one convenient in different concentration ranges. A possible configuration for heat recovery across the reactor has been also discussed to improve the efficiency of the process.

\section{REFERENCES}

[1] Zimmermann, H., Walzl, R., In Ullmann's Encyclopedia of Industrial Chemistry, Wiley-VCH: Verlag GmbH \& Co., 2009.

[2] Gallo, J. M. R., Schuchardt, U., 2014, 25, 2229-2243.

[3] Bastianoni, S., Marchettini, N., Biomass Bioenergy 1996, 11, 411-418.

[4] Huber, G., Iborra, S., Corma, A., Chem. Rev. 2006, 106, 4044-4098.

[5] Althoff, J., Biesheuvel, K., De Kok, A., Pelt, H., Ruitenbeek, M., Spork, G., Tange, J., Wevers, R., ChemSusChem 2013, 6, 1625-1630.

[6] http://www.gruppomg.com/en/news/10, “http://www.gruppomg.com/en/news/10,” n.d.

[7] Rossetti, I., Lasso, J., Compagnoni, M., De Guido, G., Pellegrini, L., Chem. Eng. Trans. 2015, 43, 229-234.

[8] de las Pozas, C., Lopez-Cordero, R., Gonzalez-Morales, J. A., Travieso, N., Roque-Malherbe, R., J. Mol. Catal. 1993, 83, 145-156.

[9] Zhang, M., Yu, Y., Ind. Eng. Chem. Res. 2013, 52, 9505-9514.

[10] Xin, H., Li, X., Fang, Y., Yi, X., Hu, W., Chu, Y., Zhang, F., Zheng, A., Zhang, H., Li, X., J. Catal. 2014, 312, 204-215.

[11] Rossetti, I., Compagnoni, M., Finocchio, E., Ramis, G., Di Michele, A., Millot, Y., Dzwigaj, S., Appl. Catal. B Environ. n.d., submitted.

[12] Sun, J., Wang, Y., ACS Catal. 2014, 4, 1078-1090.

[13] Tago, T., Konno, H., Ikeda, S., Yamazaki, S., Ninomiya, W., Nakasaka, Y., Masuda, T., Catal. Today 
2011, 164, 158-162.

[14] First, E. L., Gounaris, C. E., Wei, J., Floudas, C. a., Phys. Chem. Chem. Phys. 2011, 13, 17339.

[15] Rossetti, I., Biffi, C., Bianchi, C. L., Nichele, V., Signoretto, M., Menegazzo, F., Finocchio, E., Ramis, G., Di Michele, A., Appl. Catal. B Environ. 2012, 117-118, 384-396.

[16] Rossetti, I., Lasso, J., Nichele, V., Signoretto, M., Finocchio, E., Ramis, G., Di Michele, A., Appl. Catal. B Environ. 2014, 150-151, 257-267. 